\title{
Anatomy of Knowledge Bases used in Design Science Research
}

\section{A Literature Review}

\author{
Oliver Gaß ${ }^{1}$, Norbert Koppenhagen ${ }^{1}$, Harald Biegel ${ }^{2}$, Alexander Mädche ${ }^{1}$, Benjamin \\ Müller ${ }^{1}$ \\ ${ }^{1}$ University of Mannheim, Chair of Information Systems IV, Mannheim, Germany \\ \{gass, koppenhagen, maedche, mueller\}@eris.uni-mannheim.de \\ ${ }^{2}$ University of Mannheim, Mannheim, Germany \\ harald.biegel@googlemail.com
}

\begin{abstract}
Several papers have addressed the theory foundation of DSR. While researchers usually emphasize that the existence of such a knowledge base (KB) is essential for high quality design science research (DSR), opinions depart what kind of knowledge comprises such a knowledge base and which qualitative requirements apply regarding the knowledge leveraged. Some researchers demand that DSR is based on descriptive formal theories, while other scholars extend the width of the knowledge base also to unverified empirical evidence, conceptual knowledge and prescriptive knowledge. In order to provide some guidance for practical DSR, we apply literature review methodology on recent DSR articles to determine the common practice regarding the use and development of knowledge bases in previous projects. Based on this investigation, we discuss current issues, derive implications for future research and suggest measures to strengthen the role of the knowledge base in DSR.
\end{abstract}

Keywords: Design Science Research, Literature Review, Theory Base

\section{$1 \quad$ Introduction}

The design science approach originally goes back to engineering and has since gained significant attention in the domain of information systems (IS) research. Starting in the 60s and 70s, scholars mainly focused on distinguishing the design science research (DSR) paradigm from positivist research approaches in natural science and social sciences [1]. By that time Simon laid the foundation of the science of design in mathematics and defined designing as a search process within a closed solution space resulting in an optimized design or respective optimum [2]. Later on, researchers seemed to lose sight on design science until the beginning of the 1990s, when a variety of scholars revived design science research (DSR) in information systems (IS): Walls et al. [3] for example, broke new ground when they investigated design in light of descriptive knowledge in information systems and formulated the information system design theory (ISDT). They concluded that rigor design science research in in-

adfa, p. 1, 2011.

(C) Springer-Verlag Berlin Heidelberg 2011 
formation systems must be informed by formal theories. Since then, much work has been published trying to define the paradigmatic nature of information system research as a design science. Such research included the ontology of design science, especially addressing the place of an artifact in its context [4-7] and the epistemology of design science, investigating the nature of the underlying knowledge base and the outcome of design science in the form of a design theory [8],[9]. Others focused on the methodology of design science by proposing particular methods to create and evaluate designs [10],[11]. By now, several papers have been published on the theory foundation of DSR. Van Aken, for example, states that, "one can design an aero plane wing on the basis of tested, technological rules, but such wings can be designed much more efficiently on the basis of tested and grounded technological rules, grounded on the laws and insights of aerodynamic and mechanics" [12, p.228]. The knowledge base of DSR comprises the theories leveraged and serves as input to DSR by providing evidence that links a design, its instantiation as an artifact and its formal representation (i.e., a design theory), to the context the design is intended to operate in. It serves to explain and predict the functionality of a design and can be used to formulate testable propositions to evaluate its impact (compare the five theory types in IS as defined by Gregor [13]). Whereas there seems to be almost an agreement on the importance of the presence of such a knowledge base in literature, the questions of what kind of knowledge exactly constitutes it and which qualitative requirements apply, remain unanswered: Though, several scholars have already tackled the topic and suggested numerous definitions and requirements for the knowledge base, the variety and divergence of their suggestions still leaves it up to the individual researchers to decide upon which theoretical framing to adopt for their own work. Our paper wants to contribute to the on-going discussion by investigating the common practice in DSR: we seek to shed light on the type and origin of knowledge that constitutes the knowledge base of DSR projects. Our analysis is guided by the following research question: What is the anatomy of knowledge bases used as input for design science research in the IS field?

Following our research questions, we focus our investigation on knowledge that serves as an input to DSR and do not intend to explicitly investigate the nature of knowledge that results from DSR projects (however we consider it as a valid input). In order to address the research question, we use the literature review methodology to determine the types of knowledge base used in published information systems and computer science design science projects. Based on this investigation, we discuss current issues, derive implications for future research and suggest measures to strengthen the role of the knowledge base in DSR.

The paper is structured as follows: chapter 2 provides an overview of several definitions of the knowledge base used in DSR, chapter 3 outlines our research methodology, chapter 4 presents the results, chapter 5 discusses the findings and chapter 6 summarizes the paper, discusses identified limitations and gives an outlook on future work. 


\section{Related Work}

In order to determine the role of theory in DSR, it is important to examine previous work on the nature of theories in IS: Iivari [4] proposes a three-level-structure to describe the epistemology of DSR: he includes three categories of knowledge applicable for DSR: 1) Conceptual knowledge includes concepts, classifications and conceptual frameworks. 2) Descriptive knowledge comprises observational facts, empirical regularities, theories and hypotheses. 3) Prescriptive knowledge builds on design product knowledge including characteristics of an artifact, e.g., idea, concept, style or behavior and design process knowledge including technological norms and rules, determining how to achieve an intended outcome in a particular situation.

Another way to classify theories in the context of DSR is the simplified taxonomy of Kuechler and Vaishnavi [14]. They distinguish between two types of theories: 1) Descriptive theories originating from natural science and social science which serve as an input to design science by "suggest(ing) novel techniques or approaches to IS design problems". 2) Prescriptive theories which "give explicit prescriptions of "how to do something"' [14, p.2f].

Analyzing previous work on the qualitative requirements regarding the knowledge base which is used to inform DSR, there are three major opinions in literature: First, a major contribution to the definition of this "body of knowledge" of design science has been provided by Nunamaker et al. [15] and Walls et al. [3]. Both works emphasize that design science research must be founded on and respectively informed by a comprehensive body of knowledge. Walls et al. depict four essential parts of a IS design theory: kernel theory, meta-requirements, meta-design and testable design product hypothesis. The term kernel theory, in this context, refers to the encompassed descriptive knowledge (resulting from the knowledge base) in the meta design and the meta design process. In the understanding of Walls et al. [3] this descriptive knowledge is comprised of formal theories resulting from a variety of research fields, most notable natural science and social science. Kernel theories, following their argument, serve the purpose to add truth value to a design, allowing to formulate testable propositions about the design product or the design process. However, formal theories usually build on well-defined assumptions and include rather theoretical concepts, which limit their explanatory power for more specific practical problems. Respectively, they can only provide limited truth value in particular matters. Therefore, second, Markus et al. [9] stress that the applicability of the descriptive knowledge for a particular issue is an essential factor for selecting the underlying knowledge base. Hence, they extend Walls et al.'s [3] definition of the knowledge base to practitioners' theories-in-use (PTiU) as a more applicable descriptive knowledge. In contrast to academic theories which constitute formal theoretical concepts, a PTiU includes everyday concepts from the world of practice. Although PTiUs do not make claims about some objective truth, they make claims about how to do something effectively in a particular situation. Even though, PTiUs lack the wide scope of formal theories, they can add truth value to a design too [16]. Kuechler and Vaishnavi [14] emphasize the same issue and propose a new type of theory to solve the limited explanatory power of formal theories. They introduce the term mid-range theory (MRT) to DSR. According to their defini- 
tion, Mid-range theories in IS refer to formal theories that have been enriched with more explanatory knowledge to make them more applicable for particular problems. Finally, third, Gregor and Jones [8] extend the scope of the knowledge base even further; they use the term justificatory knowledge (JK) when referring to the knowledge base. Similar to Walls et al. [3], justificatory knowledge is an important part of a design theory which comprises eight components: 1) Purpose and scope, 2) Constructs, 3) Principles of form and function, 4) artifact mutability, 5) testable propositions, 6) justificatory knowledge, 7) implementation and 8) expository instantiation. Justificatory knowledge in their understanding is defined as the "justificatory, explanatory knowledge that links goals, shape, processes and materials" [8, p.326]. This includes knowledge from natural science or social science, PTiUs, (predictive) design theories as the result of previous DSR and also evidence-based justification as seen in medical research and action research [12]. Though, they stress the importance of an existing knowledge base, they accept lower qualitative requirements regarding the leveraged knowledge: their understanding includes also incomplete descriptive knowledge and practical evidence [8]. In this matter they concur with other researchers, for example Simon [2] who argues that the underlying descriptive knowledge doesn't have to be completely understood. Also, Hevner et al. [10] support this opinion: they state that design science is issue driven, rather than theory-driven, and hence the range of possible theoretical background should not be limited too much. Groaning et al. [17] argue that the knowledge used as JK does not necessarily need a scientific research background, but also allows additional knowledge.

\section{$3 \quad$ Methodology}

In order to determine the current role of theory in DSR we used literature review methodology. Our research design followed Webster and Watson who propose a concept-centric approach for literature reviews [18]. In detail, they suggest a framework containing five major steps: 1) Identification of relevant disciplines, 2) Selection of adequate journals and conferences, 3) Search process, 4) Structuring the content and 5) Content analysis.

Regarding the selection of relevant research disciplines, we focused on research disciplines which revolve around the nature of an IT artifact and its relation to a social context. This lead us to the obvious decision to pick information systems as the first relevant research discipline. Second, computer science, as a discipline which targets the theoretical foundations of computing and information, displayed another relevant discipline. However, computer science appears to be a wide discipline including many sub-fields which do not all directly address the design, implementation and evaluation of information system related artifacts. Therefore, we limited our research to three relevant sub-fields: The first one was software engineering which focuses on the systematic development of software, i.e., the design and development of a software artifact. The second was human-computer-interaction ( $\mathrm{HCI})$ which focuses on the study, planning, and design of the interaction between users and computers, i.e., the investigation of the interaction of particular IT artifacts with their environment. The 
third one was information technology (IT) which revolves around the development of artifacts to process or model information. The next step included the selection of appropriate journals and conferences (see Table 1). In order to bridge the gap between objectiveness and relevance, we considered two categories of outlets and conferences: First, those which publish a wide variety of research topics (e.g., IS journals) and second those which address topics comprising a major design component (e.g., software engineering journals).

Table 1. Investigated Literature Sources

\begin{tabular}{lll}
\hline & Conference & Journal \\
\hline IS & American Conference on In- & European Journal on Information Sys- \\
formation Systems & tems \\
& European Conference on In- & Information Systems Journal \\
formation Systems & Information Systems Research \\
International Conference on & Journal of the Association for Infor- \\
& Information Systems & mation Systems \\
& & Journal on Management Information \\
& & Systems \\
& & Management Information Systems Quar- \\
& & terly \\
Hawaii International Confer- & Transactions on Information Systems \\
& IEEE Computer \\
ence on System Science & IEEE Personal Communication \\
Conference on Human Factors & IEEE Internet Computing \\
in Computing Systems & IEEE Software \\
HCI International Conference & Computer Supported Cooperative Work \\
Conference on Research and & International journal of HCI \\
Development in Information & Journal of Organizational and End-User \\
Retrieval & Computing \\
International Conference on & Personal and Ubiquitous Computing \\
Management of Data & Communications of the ACM \\
& ACM Transactions on Computer Human \\
& & Interactions \\
& & ACM interactions \\
\hline Total & $\mathbf{1 8}$ \\
\hline
\end{tabular}

The next step was to decide upon a feasible time span for our investigation. As first search run with the key word "design science" did not lead to any search results previous to 1980. Additionally, all the cited related work dates after 1990. Accordingly, we narrowed down the search period to the last three decades.

SE, HCI and IT

2 Mixed IS/IT conference, here categorized as IT 
The wide selection of journals and conferences made defining a search strategy difficult. The first promising attempts on a few databases do not necessarily indicate a successful search result in total. Hence, we refined our search strategy first before conducting the actual study. The development of our search strategy followed an iterative approach: each cycle included a test run with the current search strategy, followed by an assessment of the search results and a subsequent refinement of the strategy. As a starting point, we analyzed several of the most cited articles on design science to identify an initial set of key words for the search strategy. Hevner et al.'s [10] observe that DSR exhibits a problem solving character [10]. Other literature sources define goal orientation as the key element of DSR [4]. In addition, nearly all articles name IT artifacts as a basic module for a design theory [2], [4], [10], [19]. The first test runs with different combinations of these key words and logical operators yielded a satisfying number of relevant articles. A short analysis of the findings displayed that almost every article identified, included an introduction to the methodology of DSR, mentioning the key word "design science" at least once. Exceptions to this rule were some articles focusing on design theories which do not mention "design science" explicitly. Hence, the search strategy identified as sufficient comprised an ORcombination of "design science" and "design theory". The final search run yielded 337 articles. After skimming and scanning the results and discarding all articles which $\mathrm{d}$ not display methodological or applied DSR, the final results comprised 67 articles about design science.

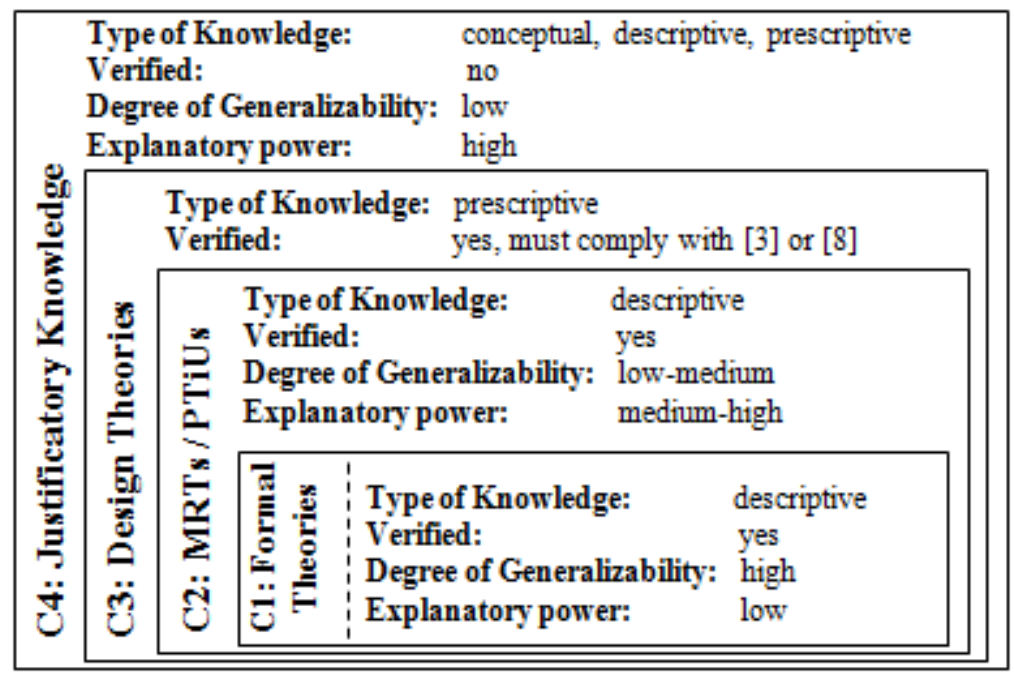

Fig. 1. Categories of knowledge bases applied for clustering

The next step included the clustering of the search results along the following dimensions: First, we defined four main categories of knowledge base used in the articles reflecting different epistemological characteristics introduced in the related work section (compare Fig. 1): the first category comprises formal theories. This kind of 
theory complies with the rather strict interpretation of the knowledge base as suggested by Walls et al. [3]. The second category also contains mid-range theories as proposed by Kuechler and Vashnavi [14] and practitioner theories-in-use as suggested by Markus et al. [9]. The third category includes also results from previous DSR in the form of prescriptive theories. The theories have to comply with the definitions of Walls et al. [3] or Gregor and Jones [8]. The fourth category represents the least strict definition of the knowledge base (e.g. [2],[8]). It includes conceptual knowledge, (descriptive) practical evidence and also preliminary prescriptive results of DSR. Regarding the distinction between the different types of theory, we followed mainly the criteria type of knowledge (descriptive, prescriptive, conceptual [4]), degree of generalizability, explanatory power for a particular problem class and whether the knowledge was scientifically verified. If several types of knowledge were used, the segmentation was conducted based on the least formal knowledge leveraged in the article.

Table 2. Segmentation of methodological DSR articles

\begin{tabular}{lll}
\hline Category & Information Systems & Computer Science \\
\hline Formal Theory & {$[3][21][22][23]$} & \\
$\begin{array}{l}\text { MRT / PTiU } \\
\text { Design Theory }\end{array}$ & {$[19][24][25]$} & {$[26]$} \\
JK & {$[8][10][27][28][17][29]$} & {$[30]$} \\
\hline
\end{tabular}

The manifold nature of the implemented knowledge bases made a categorization based on key words not feasible. Instead, we had to skim and scan each article to derive the type of knowledge used (compare [20]). This step was conducted by two researchers. Conflicts, especially regarding the classification of MRTs / PTiUs, were discussed and resolved. Additional to the segmentation along the types of knowledge base, we applied several other dimensions to cluster the results: One differentiator was whether the article described the methodology of DSR (Table 2) or whether the authors applied DSR methodology in a research project (Table 3).

Articles about DSR methodology usually do not apply a knowledge base practically; however they promote a specific interpretation of the knowledge base which should be applied in DSR. The analysis of the utilized knowledge also enabled the identification of its originating research discipline. We used a simplified taxonomy to structure the disciplines and sub-disciplines. We distinguished between natural science, including physics and mathematics but not computer science (CS), social sciences including all sub-disciplines such as psychology or sociology but not information systems (IS) and a category for various disciplines which includes all articles that utilize more than one of the latter (sub-) disciplines as a source of their knowledge base.

Furthermore, we analyzed the types of artifact which are investigated in the DSR project. We distinguished between four types of artifacts: constructs (vocabulary and symbols), methods (algorithms and practices), models (abstractions and representations) and instantiation (software components and information systems) [15],[30]. 
The publication target is determined by whether an article was published in a journal or a conference. We did not apply any further rankings to define an order within these two categories. All articles were assigned to the different categories disjointedly.

Table 3. Segmentation of applied DSR articles

\begin{tabular}{llll}
\hline Category & Origin & Information Systems & Computer Science \\
\hline Formal & Natural Science & {$[31][32]$} & \\
Theory & Social Science & {$[33][34][35][36]$} & {$[40][41][42]$} \\
& & {$[37][38][39]$} & \\
MRT / PTiU & CS & {$[43][44]$} & \\
& Social Science & {$[45]$} & {$[46][47][48][49]$} \\
& IS & {$[50]$} & \\
& Various & {$[9][51][52]$} & \\
Design Theory & IS & {$[53][54][55][56]$} & \\
JK & CS & {$[57][58][59]$} & \\
& Social Sciences & {$[60][61][62][63]$} & {$[70][71]$} \\
& IS & {$[64][65][66][67]$} & \\
& & {$[68][69]$} & \\
& & {$[72][73][74][75]$} & {$[78][79][80][81]$} \\
& Various & {$[76][77]$} & {$[82]$} \\
\hline
\end{tabular}

\section{$4 \quad$ Results}

Table 4 presents an overview of the number of methodological and applied DSR articles and the category of knowledge base they promote (methodological) or the category of knowledge base they implement (applied DSR). We identified 14 papers on DSR methodology and 53 papers which apply DSR methodology to address a research topic. All methodological articles share that they suggest at least some kind of knowledge base. We did not encounter any articles which deny the importance of an underlying knowledge base for DSR altogether. Knowledge bases built on formal theories are promoted by four articles, the application of MRT / PTiU for the knowledge base also by four. Six methodological articles advertise a less formal interpretation of the knowledge base.

Table 4. Categorization results in absolute numbers

\begin{tabular}{lll}
\hline Category & Method & Practical \\
\hline Formal Theory & 4 & 12 \\
MRT / PTiU & 4 & 8 \\
Design theory & 0 & 3 \\
JK & 6 & 30 \\
\hline Total & $\mathbf{1 4}$ & $\mathbf{5 3}$ \\
\hline
\end{tabular}


We could not identify any articles which solely solicit design theories as underlying knowledge. However, most authors of methodological papers who suggest a wide interpretation of the knowledge base also consider design theories as a valid part of it (Table 4). Our analysis uncovered an apparent preference (30 articles) for a wide interpretation of the knowledge base.

Table 5. Origin of KB in absolute numbers

\begin{tabular}{lcccccc}
\hline Category & $\begin{array}{c}\text { Natural } \\
\text { Science }\end{array}$ & $\begin{array}{c}\text { Social } \\
\text { Science }\end{array}$ & IS & CS & Various & Total \\
\hline Formal Theory & 2 & 10 & & & & 12 \\
MRT / PTiU & & 1 & 4 & 2 & 1 & 8 \\
Design Theory & & 3 & 12 & 4 & 11 & 3 \\
JK & & $\mathbf{1 4}$ & $\mathbf{1 8}$ & $\mathbf{6}$ & $\mathbf{1 2}$ & $\mathbf{5 3}$ \\
\hline Total & & & & &
\end{tabular}

Formal theories and MRT / PTiU also find widespread application (20 articles). Examples for formal theories originating from the social sciences are the "theory of symbolic representation" [36] or the "social constructive learning theory" [41]. Examples for theories originating from the natural sciences are the "theory of form" [40] or the "recursion theory" [32]. Examples of mid-range theories are the two major IS theories, such as the "technology acceptance model" and its derivations [47], [48], [49] or the "task-technology-fit model" [50].

Only three papers leverage a design theory [9], [51], [52]. In all three cases, the papers use the "design theory for emergent knowledge processes" [9], [51], [52]. Even though, we identified many articles which also implement results from previous DSR in their knowledge base, for example enterprise integration patterns or meta models, these previous results do not comply with the definition of a design theory as provided by Walls et al. [3] or as provided by Gregor and Jones [8] and were therefore classified as justificatory knowledge only.

The origins of justificatory knowledge are manifold. Researchers apply conceptual, prescriptive and descriptive knowledge of a variety of disciplines and sub-disciplines. Often researchers leverage knowledge of more than one discipline (e.g., IS and CS knowledge) to inform their designs (11 articles). Examples for applied justificatory knowledge are agile development methods [81], system development lifecycles [56], the interaction model of SOA [54], grid-based architecture principles [82] or the wide-audience-requirement engineering method [81]. In contrast to formal theories or MRT / PTiU which often originate from other sub-disciplines of the super ordinate research field (e.g., psychological theories), justificatory knowledge is often very context specific and results from the same sub-discipline (see Table 5).

Regarding the types of artifacts (see Table 6), the most common types found are models, mostly abstractions and representations of business processes (20 articles). Almost with the same frequency appear instantiation in the form of software components, light-weight applications and full-fledged information systems. 
Table 6. Type of artifact in absolute numbers

\begin{tabular}{lcccccc}
\hline Category & $\begin{array}{c}\text { Con- } \\
\text { struct }\end{array}$ & Model & Method & $\begin{array}{c}\text { Instan- } \\
\text { tiation }\end{array}$ & $\begin{array}{c}\text { Vari- } \\
\text { ous }\end{array}$ & Total \\
\hline Formal Theory & & 1 & 4 & 7 & & 12 \\
MRT / PTiU & 1 & 2 & 2 & 3 & & 8 \\
Design Theory & & & 1 & 1 & 1 & 3 \\
JK & 2 & 16 & 2 & 7 & 3 & 30 \\
\hline Total & $\mathbf{3}$ & $\mathbf{2 0}$ & $\mathbf{9}$ & $\mathbf{1 8}$ & $\mathbf{4}$ & $\mathbf{5 3}$ \\
\hline
\end{tabular}

DSR that works with model artifacts often build on related justificatory knowledge, mostly represented by conceptual knowledge in the form of meta models. Instantiations, on the contrary, rely more on formal theories ( 7 articles) and MRT/PiTU ( 3 articles). Regarding the correlation between the publication target and the type of knowledge base used (see Table 7), our analysis shows that DSR published in journals leverage a higher percentage $(58,9 \%)$ of scientific theories (Formal theories, MRTs/ PTiUs and Design Theories). DSR which is published in conferences instead, mostly relies on context specific, but scientifically less verified justificatory knowledge (64.9\%). Furthermore, DSR which targets the development of models and does not implement a comprehensive knowledge base based on formal theories are usually published only in conferences.

Table 7. Publication target in absolute and relative numbers

\begin{tabular}{lcc}
\hline Category & Conference & Journal \\
\hline Formal Theory & $6(16.2 \%)$ & $6(35.3 \%)$ \\
MRT / PTiU & $6(16.2 \%)$ & $2(11.8 \%)$ \\
Design Theory & $1(2.7 \%)$ & $2(11.8 \%)$ \\
JK & $23(64.86 \%)$ & $7(41.1 \%)$ \\
\hline Total & $\mathbf{3 6}(\mathbf{1 0 0} \%)$ & $\mathbf{1 7 ( 1 0 0 \% )}$ \\
\hline
\end{tabular}

\section{Discussion of Results}

In general, all DSR works utilize one or various knowledge sources and none of the ones in our sample negate the necessity of a solid knowledge base. The first core finding is the more or less equal distributions of theory grounded articles and justificatory knowledge based articles (23 vs. 30 articles). In particular, the research papers originating from the IS field reflect an equal distribution (20 vs. 23 articles) whereas we observe a tendency towards JK based grounding in the CS discipline (3 vs. 7 articles). However, the significantly lower number of identified DSR papers in CS does does not seem to allow for drawing reliable conclusions. The slightly higher number of articles that build their research on justificatory knowledge (30 articles) as compared to theory grounding ( 23 articles) can be explained by the fact that DSR is often problem driven [10]. When solving a concrete problem, a researcher's first choice seems 
to be mostly knowledge that is closely related to the problem and can provide a high degree of explanatory power for the particular context. Such knowledge results usually form related research or is collected empirically by the researchers themselves as our analysis shows. Formal theories seem to be only the second choice: especially when researchers attempt to generalize their results, theories are used to frame the results into a wider context. Very rarely is a DSR project initiated in response to the need to further prove descriptive theories or to extend results from previous DSR research. More surprising is the finding that the distribution of methodological articles does not show a significant tension towards theory grounding ( 8 vs. 6 ). With regard to articles that promote formal theories in contrast to justificatory knowledge, we detected that a majority of articles address theory grounding from a paradigmatic perspective. Another way to promote theory integration in DSR could be to provide researchers with more concrete guidelines how to utilize formal theories in their work. For example, how can theory X from social science be used in DSR to address problem class Y.

The second finding is that the origin of knowledge shows a clear focus on IS and social science rooting. This phenomenon could be explained by the abstraction level of how technology is analyzed in the course of DSR: DSR in IS usually focuses on the application of technology in a social context. Technology is often examined from a rather abstract point of view and not elaborated in detail. Social science theories seem to be more applicable than natural science theories in this case since they include constructs for various social factors and sometimes also provide constructs to cover technological aspects. However, we need to point out that according to our data this statement applies only on the level of formal theories and when the artifact is an instantiation (e.g., a full-fledged IS). DSR research which focuses on very specific design problems (e.g., models), does not solely rely on formal theories from social science but utilizes knowledge from various disciplines. The explanatory power of the leveraged knowledge seems to be the most important factor in this case; no matter what the origin of the knowledge is. Also, more technology focused DSR projects, especially in the CS domain (e.g., algorithm design), draw greater benefits from CS or natural science theories and justificatory knowledge. These disciplines seem to be perceived as offering better theories for the design and advance of solutions to technical problems.

The third finding is that design theories are rarely utilized as knowledge base in DSR projects. The explanation for this deficit could be twofold: i) lack of design theories and ii) existing DSR theories are not applicable. Both statements are supported by the fact that we found only one DT, which is actually utilized three times in DSR projects, the "Design theory for emergent knowledge processes" suggested by Markus et al. [9]. Specifically analyzing this design theory, one could condense the following key features: 1) the design theory is based on an established framework for information system design theory, 2) it is highly generalized regarding its context (emergent knowledge creation) and characteristics (impossibility to predict process participation and tool usage, knowledge distribution, and emergent processes) and c) it is highly tangible in terms of the artifact, applicable requirements, recommendations, system design and development principles. One could argue that these features are 
relevant prerequisites for a design theory to be utilized in later DSR. However, these high qualitative requirements which seem to be hardly ever met are also a probable explanation for why only few design theories exist which are applicable for further DSR research. We think additional methodological work should aim on clarifying the nature of design theories and also provide practical guidelines how to create applicable design theories.

A fourth finding is that DSR work published in journals leverages a higher percentage of (formal) theories in contrast to DSR which is published on conferences. As the evaluation of the scientific quality of particular outlets or the rigor and relevance of DSR projects is out of scope, we can only speculate about the reasons: One possible explanations could be that DSR work addressing real world problems is more often found on conferences, and such targeting the development, verification or extension of theories more often in journals.

\section{Conclusion, Limitations and Future Work}

Our literature review on the anatomy of the knowledge base in DSR lead to the following results: 1) There is no extreme - both formal and less formal knowledge are used for the knowledge base of DSR in IS and CS. 2) Researchers harness knowledge from a variety of disciplines, however there is a tendency towards the use of social science and IS knowledge. 3) Design theories play almost no role for the knowledge base. 4) DSR research published in journals leverages more formal knowledge, while those published on conferences more informal. Our work is subject to several limitations: first, we cannot obviate that we have missed important work on DSR in IS. Second, we are aware of the fact that we couldn't cover all IS and especially CS literature sources which are potential targets of DSR. Third, our results are very dependent on our segmentation of the knowledge bases applied. While methodological articles on the nature of the knowledge base provide a good basis for segmentation of social science theories, natural science theories, especially leveraged CS theories and theorems, often do not fit in these patterns. In addition, it was not always clear to which research discipline an article belonged, especially when an outlet addressed both CS and IS topics (e.g. HICSS). Despite the shortcomings of our study, we believe that our research succeeds in shedding some light on the anatomy of the knowledge bases used in DSR. Especially our third finding reveals a critical issue since a significant number of DSR scholars stress the importance of DTs as the outcome (e.g., [3]), and more importantly, contribution to the scientific knowledge base. Therefore, the lack of applied design theories raises the question if previous DSR has already made these contributions and if not why. As concluded, further methodological work could help to achieve some clarity here. In addition, our results offer the possibility to investigate further correlation between the category of the knowledge base and the quality of DSR works. A more comprehensive study, using official rankings, could show the type of KB used in high quality publications. Citation backtracking could reveal a connection between the KB used and the amount of citations of an article. 


\section{References}

1. Orlikowski, W., Baroudi, J.: Studying information technology in organizations: Research approaches and assumptions. Information systems research 2(1), 1-28 (1991)

2. Simon, H.: The sciences of the artificial 3rd edn. Cambridge and Mass: MIT Press (1996)

3. Walls, J., Widmeyer, G., El Sawy, O.: Building an information system design theory for vigilant eis. Information Systems Research, 3(1), 36-59 (1992)

4. Iivari, J.: A paradigmatic analysis of information systems as a design science. Scandinavian Journal of Information Systems 19(2), 39- 64 (2007)

5. Orlikowski, W., Iacono, C.: Research commentary: desperately seeking the 'IT' in IT research-A call to theorizing the IT artifact. Information systems research 12(2), 121-134 (2001)

6. Benbasat, I., Zmud, R.: The identity crisis within the IS discipline: Defining and communicating the discipline's core properties. Mis Quarterly, 183-194 (2003)

7. Baskerville, R.: What design science is not. European Journal of Information Systems 17(5), 441-443 (2008)

8. Gregor, S., Jones, D.: The anatomy of a design theory. Journal of the Association for Information Systems 8(5), 313-335 (2007)

9. Markus, M., Majchrzak, A., Gasser, L.: A design theory for systems that support emergent knowledge processes. MIS Quarterly 26(3), 179-212 (2002)

10. Hevner, A., March, S., Park, J., Ram, S.: Design science in information systems research. MIS Quarterly 28(1), 75-105 (2004)

11. Sein, M., Henfridsson, O., Purao, S., Rossi, M., Lindgren, R.: Action design research. MIS Quarterly 35(1), 37-56 (2011)

12. Van Aken, J.: Management research as a design science: Articulating the research products of mode 2 knowledge production in management. British Journal of Management 16(1), 19-36 (2005)

13. Gregor, S.: The nature of theory in information systems. Management Information Systems Quarterly 30(3), 611 (2006)

14. Kuechler, B., Vaishnavi, V.: Theory development in design science re search: anatomy of a research project. European Journal of Information Systems 17(5), 489-504 (2008)

15. Nunamaker, J., Chen, M.: Systems development in information systems research. In : Proceedings of the Twenty-Third Annual Hawaii International Conference on System Sciences, pp.631-640 (1990)

16. Sarker, S., Lee, A.: Using a positivist case research methodology to test three competing theories-in-use of business process redesign. Journal of the Association for Information Systems 2(1) (2002)

17. Groaning, A., Wendler, R., Leyh, C., Strahringer, S.: Rigorous selection of input artifacts in design science research - tavias. In : Processings of the 16th Americas Conference on Information Systems (2010)

18. Webster, J., Watson, R.: Analyzing the past to prepare for the future: Writing a literature review. MIS Quarterly 26(2), xiii-xxiii (2002)

19. Kuechler, B., Park, E., Vaishnavi, V.: Formalizing theory development in is design science research: Learning from qualitative research. In : Proceedings of the 15th Americas Conference on Information Systems (2009)

20. Machi , L., McEvoy, B.: The literature review: Six steps to success 1st edn. Thousand Oaks: Corwin Press (2009)

21. Buckl, S., Matthes, F., Schweda, C.: Utilizing patterns in developing design theories. In : Proceedings of the 31 st International Conference on Information Systems (2010) 
22. Gregory, R.: Design science research and the grounded theory method: Characteristics, differences, and complementary uses. In : Proceedings of the 18th European Conference on Information Systems (2010)

23. Weber, S.: Design science research: Paradigm or approach? In : Processings of the 16th Americas Conference on Information Systems (2010)

24. Ofer, A., Kumar, N., Shapira, B.: A theory-driven design framework for social recommender systems. Journal of the Association for Information Systems 11(9), 455-490 (2010)

25. Hovorka , D., Germonprez, M.: Tinkering, tailoring and bricolage: Implications for theories of design. In : Proceedings of the 15th Americas Conference on Information Systems (2009)

26. Zimmerman, J., Forlizzi, J., Evenson, S.: Research through design as a method for interaction design research in hci. In : Proceedings of the 2007 Conference on Human Factors in Computing Systems CHI 2007, New York, p.493 (2007)

27. Gonzalez, R.: Validation of crisis response simulation within the design science framework. In : Proceedings of the 30th International Conference on Information Systems (2009)

28. Roland, M., Thoring, K.: Understanding artifact knowledge in design science: Prototypes and products as knowledge repositories. In : Proceedings of the 17th Americas Conference on Information Systems (2011)

29. Weedman, J.: Client as designer in collaborative design science research projects: what does social science design theory tell us? European Journal of Information Systems 17(5), 476-488 (2008)

30. Hevner, A., March, S.: It systems perspectives -the information systems research cycle. Computer 36(11), 111-113 (2003)

31. Woolridge, R., Hale, J., Hale, D.: Towards a reference architecture of intent for information systems strategic alignment. In : Proceedings of the 14th Americas Conference on Information Systems (2008)

32. Heinrich, B., Bolsinger, M., Bewernik, M.: Automated planning of process models: The constructions of exclusive choices. In : Proceedings of the 30th International Conference on Information Systems (2009)

33. Chatterjee, S., Sarker, S., Fuller, M.: A deontological approach to designing ethical collaboration. Journal of the Association for Information Systems 10(3), 138-169 (2009)

34. Siponen, M., Baskerville, R., Heikka, J.: A design theory for secure information systems design methods. Journal of the Association for Information Systems 7(11), 725-770 (2006)

35. Zhang, , Brown, S.: Designing collaborative systems to enhance team performance. Journal of the Association for Information Systems 12(8), 556-585 (2011)

36. Kasper, G.: A theory of decision support system design for user calibration. Information Systems Research 7(2), 215-232 (1996)

37. Xu, J., Wang, G., Li, J., Chau, M.: Complex problem solving: Identity matching based on social contextual information. Journal of the Association for Information Systems 8(10), 525-545 (2007)

38. Mittleman, D.: Planning and design considerations for computer supported collaboration spaces. Journal of the Association for Information Systems 10(3), 278-305 (2009)

39. Vranesic , H., Rosenkranz, C.: The role of boundary objects and boundary spanning in data warehousing -a research-in-progress report. In : Proceedings of the 17th European Conference on Information Systems (2009) 
40. Steiger, D., Steiger, N.: Decision support as knowledge creation: An information system design theory. In : Proceedings of the 40th Annual Hawaii International Conference on System Sciences, p.204a (2007)

41. Zhang, X., Olfman, L., Firpo, D.: An information systems design theory for collaborative eportfolio systems. In : Proceedings of the 44th Annual Hawaii International Conference on System Sciences, pp.1-10 (2011)

42. Benjamin, S., Schooley, L., Alnosayan, N.: Development of a disability employment information system: An information systems design theory approach. In : Proceedings of the 39th Annual Hawaii International Conference on System Sciences (2006)

43. Lau, R., Liao, R., Xu, K.: An empirical study of online consumer review spam: A design science approach. In : Proceedings of the 31 st International Conference on Information Systems (2010)

44. Lau, R., Lai, C., Ma, J., Li, Y.: Automatic domain ontology extraction for contextsensitive opinion mining. In : Proceedings of the 30th International Conference on Information Systems (2009)

45. Nickerson, R., Varshney, U., Muntermann, J., Isaac, H.: Taxonomy development in information systems: Developing a taxonomy of mobile ap plications. In : Proceedings of the 17th European Conference on Information Systems (2009)

46. Becker, J., Karow, M., Mueller-Wienbergen, F., Seidel, S.: Toward process modeling in creative domains. In : Proceedings of the 15th Americas Conference on Information Systems (2009)

47. Gass, O., Mädche, A.: Enabling end-user-driven data interoperability - a design science research project. In : Proceedings of the 17th Americas Conference on Information Systems (2011)

48. Golding, P., Donaldson, O.: A design science approach for creating mobile applications. In : Proceedings of the 30th International Conference on Information Systems (2009)

49. Nan, N., Johnston, E.: Using multi-agent simulation to explore the contribution of facilitation to gss transition. Journal of the Association for Information Systems 10(3), 252-277 (2009)

50. Baloh, P.: The role of fit in knowledge management systems: Tentative propositions of the kms design. Journal of Organizational \& End User Computing 19(4), 22-41 (2007)

51. Markus, M.: Toward a theory of knowledge reuse: Types of knowledge reuse situations and factors in reuse success. Journal of Management Information Systems 18(1), 57-93 (2001)

52. Vizecky, K.: A design theory for knowledge transfer in business intelligence. In : Proceedings of the 17th Americas Conference on Information Systems (2011)

53. Collins, J., Ketter, W., Gini, M.: Flexible decision support in dynamic inter-organisational networks. European Journal of Information Systems 19(4), 436-448 (2010)

54. Hoyer, V., Stanoevska-Slabeva, K.: Generic business model types for enterprise mashup intermediaries. In : Proceedings of the 15th Americas Conference on IS (2009)

55. DevelAkesson, M., Kautz, K., Eriksson, C.: Engaged design science: oping design decisions for the future e-newspaper. In : Proceedings of the 31 st International Conference on Information Systems (2010)

56. Böhringer, M.: Towards a design theory for applying web 2.0 patterns to organisations. In : Proceedings of the 19th European Conference on Information Systems (2011)

57. Williams, K., Chatterjee, S., Rossi, M.: Design of emerging digital services: a taxonomy. European Journal of Information Systems 17(5), 505-517 (2008)

58. Urbach, N., Würz, T.: Designing a reference framework of it/is outsourcing steering processes. In : Proceedings of the 19th European Conference on Information Systems (2011) 
59. Boehm, M., Stolze, C., Breitschwerdt, R., Zarvic, N., Thomas, O.: An integrated approach for teaching professionals it management and it consulting. In : Proceedings of the 17th Americas Conference on Information Systems (2011)

60. Sarnikar, S., Deokar, A.: Towards a design theory for process-based knowledge management systems. In : Proceedings of the 29th International Conference on Information Systems (2008)

61. Chung, W., Tseng, T.-L.: Extracting business intelligence from online product reviews: An experiment of automatic rule-induction. In : Proceedings of the 31st International Conference on Information Systems (2010)

62. Umapathy, K., Purao, S., Barton, R.: Designing enterprise integration solutions: effectively. European Journal of Information Systems 17(5), 518-527 (2008)

63. Mueller, B., Ahlemann, F., Riempp, G.: Towards a strategic positioning method for it management. In : Proceedings of the 30th International Conference on Information Systems (2009)

64. Martin, J., Conte, T., Knapper, R.: Towards objectives-based process redesign. In : Proceedings of the 17th Americas Conference on Information Systems (2011)

65. Hertlein, M., Smolnik, S., Riempp, G.: Knowledge centers in professional services firms: Design and empirical evidence. In : Processings of the 16th Americas Conference on Information Systems (2010)

66. Becker, J., Weiss, B., Winkelman, A.: Developing a business process modeling language for the banking sector - a design science approach. In : Proceedings of the 15th Americas Conference on Information Systems (2009)

67. Albert, T., Goes, P., Gupta, A., Gupta, A.: Gist: A model for design and management of content and interactivity of customer-centric web sites. MIS Quarterly 28(2), 161-182 (2004)

68. Xie, J.: Sustaining quality assessment processes in user-centred health in formation portals. In : Proceedings of the 15th Americas Conference on Information Systems (2009)

69. Blinn, N., Lindermann, N., Faecks, K., Nuettgens, M.: Web 2.0 in sme networks - a design science approach considering multi-perspective requirements. In : Proceedings of the 15 th Americas Conference on Information Systems (2009)

70. Cleven, A., Wortmann, F.: Uncovering four strategies to approach master data management. In : Proceedings of the 43rd Annual Hawaii International Conference on System Sciences, pp.1-10 (2010)

71. Hain , S., Back, A.: Towards a maturity model for e-collaboration -a design science research approach. In : Proceedings of the 44th Annual Hawaii International Conference on System Sciences, pp.1-10 (2011)

72. Aaen, I.: Essence: facilitating software innovation. European Journal of Information Systems 17(5), 543-553 (2008)

73. D'Aubeterre, F., Singh, R., Iyer, L.: Secure activity resource coordination: empirical evidence of enhanced security awareness in designing secure business processes. European Journal of Information Systems 17(5), 528-542 (2008)

74. D'Aubeterre, F., Singh, R., Iyer, L.: A semantic approach to secure collaborative interorganizational ebusiness processes (ssciobp). Journal of the Association for Information Systems 9(3), 231-266 (2008)

75. Samuel-Ojo, O., Schooley, B., Hilton, B., Horan, T.: Sharing behavior in emergencies: An instantiation of a utility-focused prototype of a secure mobile near-real-time content device in pre-hospital and hospital settings. In : Processings of the 16th Americas Conference on Information Systems (2010) 
76. Andrade, E., Reynoso, J.: Enhanced learning using mutimedia-interactive systems: An experimental study. In : Proceedings of the 15th Americas Conference on Information Systems (2009)

77. Hochstein, A., Brenner, W., Schindlholzer, B.: Service consumer model: Understanding and describing consumers for new service development. In : Proceedings of the 14th Americas Conference on Information Systems (2008)

78. Gaspoz, C., Pigneur, Y.: Preparing a negotiated $\mathrm{r} \& d$ portfolio with a prediction market. In : Proceedings of the 41st Annual Hawaii International Conference on System Sciences, p.53 (2008)

79. Druckenmiller, D., Acar, W.: Engineering dialectical inquiry: Lessons learned from lab explorations. In : Proceedings of the 42nd Annual Hawaii International Conference on System Sciences, pp.1-10 (2009)

80. Rittgen, P.: Collaborative modeling -a design science approach. In : Proceedings of the 42nd Annual Hawaii International Conference on System Sciences, vol. 42, pp.1-10 (2009)

81. Schooley, B., Hilton, B., Abed, Y., Lee, Y., Horan, T.: Process improvement and consumer-oriented design of an inter-organizational information system for emergency medical response. In : Proceedings of the 44th Annual Hawaii International Conference on System Sciences, pp.1-10 (2011)

82. Weber, S., Beck, R., Wolf, M., Vykoukal, J.: Portfolio performance measurement based on service-oriented grid computing: Developing a prototype from a design science perspective. In : Proceedings of the 43rd Annual Hawaii International Conference on System Sciences, pp.1-10 (2010) 